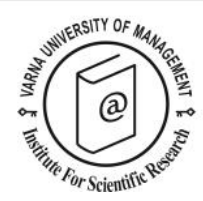

\title{
How can researchers track tourists? A bibliometric content analysis of tourist tracking techniques
}

\author{
Hugo Padrón-Ávila ${ }^{{ }^{*}}$ and Raúl Hernández-Martín ${ }^{2}$
}

\footnotetext{
${ }^{1}$ Department of Applied Economics and Quantitative Methods, Universidad de La Laguna C/ Padre Herrera s/n, 38200 San Cristóbal de La Laguna, Santa Cruz de Tenerife, Spain. Tel: +34 922317014. E-mail: hpadrona@ull.edu.es ${ }^{2}$ Department of Applied Economics and Quantitative Methods, Universidad de La Laguna

* Corresponding author
}

\begin{abstract}
In this study, an identification of tourist tracking techniques, their evolution, advantages and disadvantages is made to help researchers decide which techniques to use. First, a literature review is carried out to explain how current tracking techniques work and what information can be obtained through their use. A total of 31 different tracking techniques were found. Afterwards, a bibliometric analysis was conducted to gather data regarding studies published on tourist tracking, the evolution of these studies and the most used techniques. To do so, all empirical contributions using tourist tracking techniques found in Scopus were considered for the analysis. Results point that geolocation-based techniques currently are the most frequently used ones to track tourists. Techniques such as the direct observation of tourists were the first techniques used in tourism research but are currently in disuse. Finally, based on a further literature review, the main advantages and disadvantages of the techniques found are highlighted. The study has implications for researchers interested in tracking tourists to study their behaviour and mobility patterns. It can be also used by destination managers willing to gather data of tourists to better understand tourism activity and industry.
\end{abstract}

Keywords: tracking techniques, tourist, mobility, bibliometric analysis, behaviour

Citation: Padrón-Ávila, H. \& Hernández-Martín, R. (2020). How can researchers track tourists? A bibliometric content analysis of tourist tracking techniques. European Journal of Tourism Research 26, 2601 


\section{Introduction}

Tracking is an increasingly relevant technique in tourism studies that provides information on the behaviour of visitors within a destination (Hardy et al., 2019; Shoval \& Isaacson, 2010). Tourist tracking techniques can be used to identify the places in a destination visited by tourists (McKercher \& Lau, 2008; Shoval \& Isaacson, 2010; Shoval et al., 2011) or to identify those tourists visiting certain points of interest (Barton \& Graf, 2016; Smallwood et al., 2012). Through a literature review, it can be seen that there are techniques with similar characteristics, facilitating their classification into categories. In general, these techniques have two main focuses. They can be used to identify the places visited by a certain tourist (e.g. Raun, Ahas, \& Tiru, 2016). Alternatively, they can help determine what type of tourists visit a certain place (e.g. Izquierdo Valverde, Prado Mascuñano, \& Velasco Gimeno, 2016). Thus, techniques have been differentiated between tracking techniques from a demand-side approach (they directly track tourists) and tracking techniques from a supply-side approach (they identify which tourists visit a specific place). Moreover, using a bibliometric analysis, the evolution of the use of tourist tracking techniques and which techniques are most frequently used in tourism research can be investigated (Jiménez-Caballero \& Polo Molina, 2017). The main advantages and disadvantages of these techniques are also evaluated. Knowing the pros and cons of the techniques can be useful for researchers interested in tracking tourists to study behaviour within destinations (Raun et al., 2016).

The main benefit derived from this analysis is for researchers to know which techniques can be used in their studies and help them choose the most appropriate techniques for their aims. Indeed, choosing a suitable tracking technique is important as it determines the implications of the research. Likewise, Lau, Koo, \& Dwyer (2017) state that the implications derived from studies based on tourist tracking depend on the technique used, as each technique gathers different data. The application of a correct tracking technique may also help improve the management of tourism destinations and firms (McKercher \& Lau, 2008; Shoval \& Isaacson, 2007). The results of tracking studies can contribute to reducing the existent inequalities in the economic development of a region, controlling migration patterns of the population and distributing the incomes and wealth generated by tourism activity (Lau et al., 2017). These studies are also capable of helping researchers and managers understand the seasonality of destinations, the attractions and itineraries of certain places (Raun et al., 2016) as well as identifying tourist attractions that may have been ignored by destination managers (Alawwad et al., 2016). Raun \& Ahas (2016) even pointed to the contribution of these kinds of studies in the improvement of transport management, taxation regulations, public administrations' management, among others.

Thereby, this paper's aim is analysing how tourist tracking techniques were used by previous researchers, describe the techniques used, analyse how their use has evolved and point to the advantages and disadvantages that each technique presents. To do so, this paper has been divided in several sections. First, a literature review has been carried out to describe those techniques used in past studies. Afterwards, we detail the method applied to gather the data used to carry out this study. Later, we present a classification of tourist tracking techniques created to facilitate the analysis of our results. After this, the study shows how the use of tracking techniques has evolved along the years. After that, the advantages and disadvantages of existing tourist tracking techniques are discussed. Finally, the results are discussed, and the conclusion of the study is presented.

\section{Literature review: Description of existing tourist tracking technique}

Surveys have been the traditional data source used by tourism researchers to gather information for their studies (Eurostat, 2014). Traditional surveys used in tourism research consist of questionnaires with the objective of gathering data about tourists' characteristics, the activities they have carried out during their trip and the amount of money spent during their trip. From these data, information 
regarding the sociodemographic characteristics of the visitors, their motivations, the estimated expenditure made during the trip, the place of stay, the activities carried out and the degree of satisfaction with them, among others can be obtained. In addition, it is possible to ask tourists if they have visited a limited number of places and attractions of the destination. Surveys allow obtaining information regarding the influx of tourists to certain places and the characteristics of tourists who consume a certain type of product (East et al., 2017).

Street surveys are based on questionnaires related to tourists' itineraries during the day in which they are surveyed. They are typically carried out in places with a great confluence of tourists and are usually in the vicinity of certain tourist attractions, accommodation establishments or parking lots. Through them, tourists' sociodemographic characteristics and the places they stay can be known. However, their main contribution is to obtain data related to the activities carried out, the time and space itinerary followed, and the expenditure made. In addition, tourists can say where they have been before arriving at the site where they are being surveyed. This type of survey is typically made in places researchers are interested in studying, and they can be conducted in the form of an interview instead of using a traditional survey (Keul \& Kühberger, 1997). For example, Sandbrook \& Semple (2006) interviewed the tourists of the Bwindi National Park, once they had returned to the city to identify their behaviour during their visit to the park.

Travel diaries are a type of survey based on the completion of a daily questionnaire to know what places tourists have visited, the order of visits, how tourists have travelled from one place to another and the time when these visits occurred. Liu, Huang, \& Fu (2017) pointed out that the questionnaire can be used in the form of a survey, interview or self-administered questionnaire. In addition, the tourists surveyed must be specific groups of tourists who must be questioned daily from the first day of stay until the day of departure from the destination. On the other hand, spatiotemporal movement diaries are based on a single questionnaire carried out at the end of the trip. Tourists must state what activities they did on each day of their trips. This technique was used by Thornton, Williams, \& Shaw (1997) to analyse the behaviour of tourists to Cornwall according to their characteristics. Through these questionnaires, researchers can know the characteristics of the tourists surveyed, the activities and itineraries carried out and the place of stay during the trip. They are also able to collect information on the expenditure made to carry out these activities or the price of certain visits. Its main objective is to configure the itineraries based on tourists' accommodation establishments.

Social media have become the main tool used by tourists to let others know the destinations and places they have visited during their trips (Kádár, 2014). Social media allow sharing photographs, comments, opinions, locations, videos, etc. Thus, it is possible to search for information about a specific destination to know what contents are published about it. To do this, the search for the hashtag linked to the destination can be used, among others (such as those hashtags linked to an enterprise or attraction). With this, researchers can search for the name of a destination and to identify what the main and secondary tourist attractions of the destination are, the tourists' opinions about them and the perceived image of the destination. Barton \& Graf (2016) even managed to collect similar information through travel blogs. Other websites that can be consulted to obtain these data are opinion portals (Kirilenko et al., 2019) that allow tourists to share their experiences during and after trips. All these types of webpages work in a similar way to put tourists in contact with each other and allow them to exchange contents and opinions that can be analysed by researchers.

However, hashtags are not the only element that can be used to analyse the contents of social media. Currently, social media user can geotag all contents uploaded to one of these platforms. It is possible to 
perform a search for a specific place and see which contents have been uploaded to the platform regarding that place (Alawwad et al., 2016; Raun et al., 2016). Through the comments left by visitors, researchers can know these visitors' characteristics and motivations, the attractions they have visited to a greater or lesser extent, the opinion they have regarding certain places or activities and the image they have of the destination. In addition, there are picture processing engines that can show a 'heat map' with the places of a destination of which the greatest number of photographs have been uploaded on certain social media (Konijn et al., 2016). With these programs, it is feasible to track the places from which a user has uploaded photographs and even show in real time what kind of photographs are being uploaded to the web. An analysis of the photos uploaded to the web shows the most visited spots, the temporal itinerary of visitors, the accommodation establishment where they have stayed and places they have liked the most.

Travel fora are also configured as a type of social media. These are tools used by tourists to give information about places they have visited and the opinions they have about them (Alawwad et al., 2016). In addition, they allow assessments of the visited places and to know the experiences of other tourists in them. Through the number of comments, it is possible to identify which are the main attractions of the destination, and which are secondary ones. The assessments of these attractions are useful to determine the degree of satisfaction of tourists with them. Through these elements, the perceived image of a destination from previous visitors can be ascertained and the profile of potential tourists seeking information about it can be identified. In fact, de Oliveira \& Porto (2016) analysed TripAdvisor to create a series of indicators based on the comments left by the users of this platform.

Currently, there are several electronic devices that are able to track and locate their users (Renenger, 2001; Shoval \& Isaacson, 2007). These devices can be used to determine how tourists move within a destination and the places they visit. Several studies have proven that it is possible to give tourists a GPS tracking device to take with them throughout their trip (Lau \& McKercher, 2006; McKercher \& Lau, 2008; McKercher \& Zoltan, 2014b; Shoval et al., 2011). These devices are usually delivered in accommodation establishments and their function is to emit an intermittent signal indicating the position at which the tourists are located, which is recorded by computer software and marked on a map. Shoval \& Ahas (2016) and Thimm \& Seepold (2016) point to GPS-based techniques as the future of tourist tracking because they allow getting more precise data. In fact, the knowledge of the exact location of tourists allows the temporal and spatial itineraries to be ascertained, as well as the roads used to connect the places visited. In addition, it also allows to establish which places receive a greater or lesser influx of tourists. As the devices tend to be delivered to accommodation establishments, the location of the accommodation chosen by the tourists is also discovered. East, Osborne, Kemp, \& Woodfine (2017) delivered GPS devices to tourists at Marwell Zoo to identify the main routes taken by them when visiting this tourist attraction. The use of this technique identifies in which places of the zoo tourists spend a greater amount of time and at which times certain places of the zoo are more likely to be visited. In addition, this technique was combined with the use of surveys to establish what factors explained why tourists move in one way or another.

It is not always necessary to give tourists a device that registers their location, as other tools can be used. Shoval \& Isaacson (2007) commented that the GPS incorporated in the rental cars can be used to know the roads and car parks mainly used to travel through a destination. It is possible to find out the itineraries followed and the place of stay of the tourists studied. If this information is also complemented with the personal data held by the rental companies, the socio-demographic characteristics of the tourists can be gathered. In the same way, GPS incorporated in other means of transport can be used, such as rental bicycles or recreational boats. Other portable devices with an 
Internet connection, such as tablets or smart watches, can also be tracked. These devices can pinpoint the most and least visited places of the destination, and the spatial and temporal itineraries carried out. Although there are several geolocation based techniques that can track tourists, Yun, Kang, \& Lee (2018) pointed out that the most appropriate one is the tracking of mobile phone users. Shoval \& Isaacson (2007) stated that there are several methods that can be applied. One of them would be to activate the tracking function in each of the telephones belonging to the tourists studied by installing a tracking application. In fact, there are several studies in which this technique has been used (Alawwad et al., 2016; Dattilo et al., 2016; Hardy et al., 2017; Raun et al., 2016; Yun et al., 2018). Through these studies, it has been possible to analyse the itineraries of visitors according to visitors' characteristics and their places of stay in the destination. In addition, it can also identify the most visited tourist attractions and the transport means used to connect these attractions when visiting the destination. In fact, recent research such as the one carried out by Baggio \& Scaglione (2018) has used tourists' mobile phones to track the places visited during their visit to the destination. Another method described by Shoval \& Isaacson (2007) is to trace the origin of the electromagnetic frequencies of the active telephones in the destination during a given period. The problem with this technique is that it does not allow differentiating tourists' mobile phones from locals' ones. Finally, Shoval \& Isaacson (2007) stated that researcher can make a formal request to a telephone company for a report of the movements and characteristics of users of foreign telephone numbers in a specific destination. Foreign telephones need to connect to a local telephone networks in order to make calls and connect to the Internet, so the data of these phones are registered by the companies with which they establish a connection. Raun et al. (2016) highlight the large amounts of data that this technique can provide, although they do not apply them in their study. However, Seynaeve \& Demunter (2016) used this technique during their research with the support of a local telephone company. The technique provides visitors' characteristics, since their personal data are registered in their telephones. In addition, it allows identifying itineraries, which attractions are the most visited in the destination, how tourists have reached the places visited and where they have stayed.

Advertising is used by different tourism agents to promote products and various destination attractions. The advertising actions of tourism companies and destinations are aimed at attracting tourists interested in the tourism activities offered. Therefore, the places visited can be known through an analysis of the advertising carried out in a destination. Widespread Internet access also allows potential tourists to be informed of the places they can visit in a destination. Therefore, previous studies have suggested the analysis of the activities carried out by tourists within a destination through an analysis of tourism promotion portals and destination web pages (Alawwad et al., 2016; Buhalis \& Law, 2008; Wang et al., 2016). The pages that can be consulted are very varied. Through these web pages, it is possible to identify which the most visited tourist attractions of a destination are, although they have the disadvantage that less visited or known attractions may not appear in them. In addition, information can be gathered regarding the price of certain activities and the type of clients to whom they are oriented. This analysis also shows the image projected by public and private agents of the destination. In fact, Signorelli, Reis, \& Biffignandi (2016) analysed the information offered by the Wikipedia website to find out the characteristics of tourists from four European cities. To do this, they analysed the data of users who had visited Wikipedia pages corresponding to different tourist attractions in the cities studied. Other websites from which information can be extracted are travel blogs or search engines through tools such as Google Trends.

Web pages are not the only source to identify the places and activities promoted. Advertising brochures, web advertising, billboards on the roads in destination, videos of tourism promotion, etc. highlights the places for visitors to focus on, some of the most known places and activities in a destination, the price 
of certain activities and the image projected by the destination. It is also feasible to ask public administrations for an official list of tourist attractions in their destinations. Thus, information can be obtained on which places are visited in the zone, even if they are not promoted. However, the information that will be obtained will generally refer to most frequently visited attractions, the price to access them and the image generated by the destination.

Certain techniques show if tourists have gone to certain places. However, not all of them can show if tourists have really enjoyed the attractions they have been to, if they have accessed them or have just passed by them or photographed them from the outside. However, certain attractions have control systems that require tourists to pay an entrance fee to access them or use some type of registration system (Han et al., 2018). The revenues obtained by tourist attractions are registered and, through them, it is possible to know the number of visitors who have been to these attractions (Zoltan \& Masiero, 2012; Zoltan \& McKercher, 2015). If the price of the tickets is fixed, the division between the total revenues obtained during a specific period and the price of the ticket would result in the number of visitors during the period. If the price of the entrance varies depending on the tourist (due to age, being a resident, etc.), the agency responsible for managing revenues must record the number of tickets sold of each type, which can be verified through the tickets issued during the period analysed. This technique is especially suitable to know the price of visits to certain places, the time of completion of these activities and the influx of tourists to certain places. Some companies also have their own inflow records in which they collect data not only on the number of visitors received, but on their characteristics. Asking for this type of information provides a more in-depth analysis, as there is a greater amount of information available. Certain companies even conduct surveys of their clients to obtain even more information about them. Current research such as the studies made by Alawwad et al. (2016) and Eccleston, Hardy, \& Hyslop (2019) accepts the use of these data as valid for carrying out mobility studies and for making a characterization of the profile of the tourists of a destination. However, the study points out that it is worth bearing in mind that the technique has the limitation of analysing only those companies or public centres that have this kind of record.

It can be also known the connections used by tourists between the tourist attractions visited through the sale of destination cards (Zoltan \& Masiero, 2012; Zoltan \& McKercher, 2015). These are a special type of ticket sold by the destination managers that include, under a single price, access to various tourist attractions. The price of this ticket is lower than the sum of the individual access cost of each attraction (Zoltan \& Masiero, 2012; Zoltan \& McKercher, 2015). Zoltan \& McKercher (2015) used them to determine how tourists connect to certain tourist attractions in Switzerland. Destination cards seem to be able to provide information on which the main tourist attractions of the destination are and which ones are less visited. Their analysis also shows the money paid by visitors to perform the activities contained in destination cards.

Tourism intermediaries can merge, in the same service, the transport, accommodation and activities to be carried out in the destination. This service is known as a tour package. Hyde \& Lawson (2003) pointed out that their study allows identifying the places visited by tourists in a destination if the itineraries offered by tourism intermediaries are analysed. The web pages of these intermediaries show which activities are sold by them and the way they distribute the activities during the time of a trip. The intermediaries also have personal information of their clients, lists of the main attractions of the destinations and the activities carried out by their clients. They also know the price paid for the attractions and the places where tourists have stayed. As with intermediaries, it is also possible to analyse the places visited by tourists through the activities contracted for them by reservation managers (Alawwad et al., 2016). These managers are, in fact, computer applications that companies install on 
their web pages. These applications allow clients to book the day, timing and activity they want from those offered by the company. The company that owns the software has all the information related to the reservations made by the clients of the tourism companies that have contracted their services. Requesting this information from reservation managers provides information on places in which tourists have consumed tourism products. By having access to these reservations data, researchers can analyse the characteristics of the clients, the activities carried out, the times at which clients have booked activities and the prices paid. Another similar technique is to request this information from travel planners (Zoltan \& Masiero, 2012). They are web applications that allow visitors to choose the places they wish to visit during a trip in order to obtain a proposal of the most efficient way to make the selected visits. They differ from reservation managers in that the selection of a place does not imply making a reservation at it. On the contrary, the application acts simply as an aid for tourists to configure their itineraries before visiting the destination. The visits chosen by the users of these applications are recorded in their database (Zoltan \& Masiero, 2012). In this case, the socio-demographic characteristics of visitors can be found out and, in addition, this allows differentiating between the main and secondary attractions of the destination. The estimated expenditure they intend to make during their stay, the spatial and temporal itinerary visitors intend to follow and the place in which they will stay can also be ascertained.

Finally, there are techniques that study the movement of tourists in specific places of the destination. Traffic cameras and controls are used by Izquierdo Valverde, Prado Mascuñano and Velasco Gimeno (2016) to analyse the registration numbers of the cars that crossed the land borders in Spain and the time at which they did it. Through this analysis, they were able to gather information about tourists arriving and leaving the country and the length of their stays. This study could also be applicable to traffic cameras and controls located within destinations, which could track the itineraries and stops made by tourists' cars. Through this analysis, researchers can highlight certain characteristics of the visitors, some of the stops in their itineraries and the routes taken while travelling. In addition, certain car parks have video surveillance systems or sensors that register the vehicles that access them. Shoval and Isaacson (2007) pointed out that it is possible to use these systems to identify the places where tourists stop when making their trips. This study could establish the characteristics of car park users, the hours in which they carry out activities and the influx of tourists to certain attractions. In addition, sensors are used to monitor visitors' entrances to places, such as the entrance to certain buildings, tourist information offices, etc. Silva, Allbesmart, \& Rodrigues (2016) used these control systems to know the number of tourists that completed each of the available trails in a protected natural area of Portugal. Shoval \& Isaacson (2007) also indicated that surveillance cameras can be used to control the way tourists move within a small space, such as parks, buildings, museums or others. This technique allows identifying some of the main and secondary tourist attractions of the destination, the activities carried out, the timing of these activities and the behaviour of the visitors in the space analysed.

Certain techniques not only provide data on what places are visited, but also where tourists consume, and the amount of money spent at them. For this, researchers can analyse the spending made by tourists through their credit cards (Huang et al., 2014). In order to obtain this information, it is necessary to ask banking entities for information regarding tourists' personal data and the movements made in their bank accounts while travelling. Through this technique, researchers can identify the places where tourists have paid with their cards or where they have withdrawn money from at an ATM. This way, tourists' characteristics, the timing and typology of activities, the expense incurred in doing them and the place of stay of these tourists can be known. 
Tourism destinations themselves may have certain tools which track the places visited by tourists. The access points to free $\mathrm{Wi}-\mathrm{Fi}$ of certain destinations can register users' data who have accessed them and the time they have done it, thus providing information on places visited and the time spent in these places (Buhalis \& Law, 2008; Wang et al., 2016). When accessing one of these networks, users' personal data are extracted providing information on tourists' characteristics, their itinerary can be monitored through their connections to the network, their behaviour through the content they search for on the web, the timing when certain places were visited and the influx of tourists to certain areas. Destinations also have signs and indications in which they inform tourists which way to go to enjoy certain activities. These elements facilitate tourists' arrival at certain companies, natural spaces, historic buildings, etc. which have a significant influx of visitors. Through the analysis of these elements researchers can identify some of the most visited places at the destination (Buhalis \& Law, 2008; Wang et al., 2016). In addition, it also helps predict the way in which tourists will tend to follow their itinerary.

Another technique that provides information on how tourists visit a specific area is the on-site direct observation of tourists at a place (Koo et al., 2017; Lau et al., 2017; Smallwood et al., 2012). In fact, Thornton, Williams \& Shaw (1997) tracked tourists in the city of Cornwall to compare the data obtained through surveys regarding the places visited by these tourists. Recently the technique has been used in other studies, such as the one developed by Kiefer, Giannopoulos, Kremer, Schlieder, \& Raubal (2014). It is a technique that can be used on a local scale to know which the most and least visited places in a specific area are, the activities carried out by tourists within it and the spatial and temporal itineraries carried out in these areas. In addition, the technique can be combined with conducting surveys on the tourists followed to obtain information regarding their socio-economic characteristics (Keul \& Kühberger, 1997).

\section{Method}

With the aim of determining which techniques are currently being used by researchers to track tourists, a bibliometric content analysis of the publications indexed in Scopus has been carried out. Bibliometric analyses comprise a wide range of methodologies focused on studying previous scientific contributions. In this paper, we have complemented bibliometrics with content analysis. This technique is oriented to analysing words and terms used by studies addressing a certain topic to identify patterns and tendencies (Schreier, 2012). In this type of analyses, search results must be coded to generate data in order to achieve the findings of the study (Krippendorff, 2004). Content analysis has allowed us the identification and classification of tracking techniques in the first phase of the research.

Ginieis, Sánchez-Rebull, \& Campa-Planas (2012) pointed out that bibliometric analyses have gained importance in recent years to study certain areas in economic sciences, especially in marketing, tourism and strategic innovation. In fact, recent studies have proven that bibliometrics can be used when studying certain tourism-related topics (del Río-Rama et al., 2018; Jiménez-Caballero \& Polo Molina, 2017).

In this study, carrying out a bibliometric content analysis has been considered the best tool to use, since it identifies which techniques are currently being used, and how their use has evolved over recent years. This could allow an estimation of the expected frequency of use of these techniques in the future, what past studies point to being important (Thimm \& Seepold, 2016). A previous tourism study of Palmer et al. (2005) used content analysis to determine which statistical techniques have been more frequently used in tourism research. To elaborate this paper, the study and method used by Palmer et al. (2005) were followed. However, some differences can be noticed. They focused on determining current statistical techniques used in top journals, while the current paper analyses the evolution of tracking 
techniques over time and considers all journals, books and conference papers contained in Scopus database.

\section{Data collection}

Although there are different databases from which the analysis could have been conducted, Scopus has been chosen mainly because, as Rudchenko, Martín, \& Sánchez-Rebull (2017) stated, it is the world's largest bibliographic database indexing more than 21,0oo titles of international scientific publishers. Moreover, the use of Scopus to get data to carry out bibliometric analysis has been widely supported (del Río-Rama et al., 2018; Maldonado-Erazo et al., 2019). In addition, other bibliometric studies conducted in the field of tourism research have also supported its use (Boselie et al., 2005; GallardoGallardo et al., 2013; Jiménez-Caballero \& Polo Molina, 2017; Rudchenko et al., 2018). Rudchenko, Martín, \& Sánchez-Rebull (2017) also pointed out that another of its advantages is that it offers the possibility of looking for specific terms included in the title of the article, summary and keywords. In addition, it provides links to the websites of the editors and to the full text of the articles.

To search the publications through Scopus, the terms tourist and tracking were introduced jointly in the search engine of the platform. Thus, the database showed scientific contributions that contained both terms as part of their title, summary or keywords. The terms could be separated or together in all or just one of these three items. The search was made on February 7, 2019, so previous or subsequent searches could yield different results than those obtained. The search was carried out for all the years available on the platform, so that the evolution of the publication of articles regarding this topic could be compared. In addition, all types of communications (scientific articles, conference papers, books, etc.) were considered in order to cover a larger sample. The platform found 291 scientific contributions that fitted the conditions established. Subsequently, all the contributions obtained were accessed to verify that they all dealt with the issue of tracking tourists within destinations. This resulted in 186 publications being discarded. Most of the studies discarded did not track tourists. Many of them dealt with the tracking of the behaviour of animal species and the changes in their migratory movements due to the arrival of tourists to a specific place. Other studies were about purchase decisions taken by tourists based on tracking of the movements of their eyes when deciding which products or services to buy. In addition, seven communications were literature reviews comparing some tourist tracking techniques. However, they did not perform an empirical study of tracking, so they were also discarded. Finally, 98 scientific contributions were considered for analysis. In order to visualize the results obtained through a bibliometric analysis, figures and tables have been added. As the analysis was carried out at the beginning of February 2019, the communications sample of 2019 was not relevant. So, data related to publications made in 2019 were discarded.

Regarding the data collected in this study, the year of publication, method used, cites, authors and journals (books or conferences, in some cases) were gathered. However, the aim of this study is not performing a traditional bibliometric analysis to analyse co-citation (Leung et al., 2017), co-words (Ding et al., 2001; Leung et al., 2017), journals most likely to publish papers dealing with a certain topic (Smith \& Hazelton, 2008) or to establish which papers or authors are the most cited ones (Ioannidis et al., 2014). In contrast, this study pretends to analyse how the use of tracking techniques has evolved in tourism research and to determine which techniques have been used more frequently in recent studies to help researchers decide which technique to apply. Thereby, the year of publication and the method used were the only variables finally employed to achieve the findings of this study.

The bibliometric analysis has identified studies in which more than one technique was used, which raises the question of identifying the need for using different techniques. Raun, Ahas, \& Tiru (2016) state 
that there is no perfect technique to gather all the data that researchers may require for a study. Therefore, the combination of different techniques is key to understanding how tourists move. This implies that all techniques present certain deficiencies or problems that limit their use, as well as certain benefits that make them more convenient than others to gather data. Therefore, a second literature review was carried out to study the main advantages and disadvantages associated with the use of tourist tracking techniques.

\section{Data analysis}

In order to analyse the data, all scientific contributions found were carefully read to identify the tracking techniques used in the study. As previously mentioned, those contributions that did not deal with tourist tracking techniques were disregarded, as well as those ones based on carrying out only a literature review. The different tracking techniques used by previous studies were firstly noted down using the original terms used by the authors of all contributions to name each technique. When information about all tracking techniques was gathered, the names of the techniques were standardized. Despite most researchers tend to name tracking techniques using the same terms, some techniques showed different names in different studies. For example, travel diaries can be sometimes called trip journals or travel journals. Thus, the findings achieved when carrying out the literature review were used to name the codes of the contributions found during the bibliometric analysis.

As suggested by Krippendorff (2004) at least two coders participated during the coding process. In this case, authors addressed this task. Moreover, Krippendorff (2004) suggest that, in order to be able to enhance reliability in a content analysis based paper, coders must be independent during the coding process. It was not the case of this study, as authors divided this process into three stages. First, the exact terms used in all the studies found were noted down. Afterwards, authors independently proposed the codes to use to classify the results based on the literature review carried out. Last, authors agreed in those studies that should be eliminated and the coding to be used and classified the contributions found. Thus, as pointed by Krippendorff (2004), no reliability index can be provided in this study as authors agreed on the coding to be used before the classification of the studies. However, the reliability of our bibliometric content analysis is supported by the fact that all articles indexed in Scopus database fulfilling the criteria previously mentioned were used. In addition, two coders established the categories and assigned papers to a certain category through an iterative process.

\section{Results of the analysis of the literature review}

31 different tourist tracking techniques were identified during the literature review carried out. Some of these techniques share several characteristics, so they can be grouped and categorized to facilitate the explanation of our subsequent findings. Thus, tourist tracking techniques have been divided into six categories. The categories created are: Survey, Web analysis, Geolocation, Advertising, Sales and Specific places. The first three categories refer to techniques that allow tourists to be tracked from a demand-side approach as they focus on analysing tourists' behaviour to understand the places they have visited. The last three correspond to techniques aimed at tracking tourists from a supply-side approach because they focus on studying places to establish if they receive tourists or not. All the techniques allow the identification of at least one of the places visited by tourists when traveling to a destination. In addition, some techniques also gather other types of data to improve the findings of the studies carried out. An explanation of the categories created is provided in Table 1, while Table 2 and Table 3 contain the techniques included in each category. 
Table 1. Categories created to classify tourist tracking techniques

\begin{tabular}{ll}
\hline Category & Description \\
\hline Survey & $\begin{array}{l}\text { Techniques consisting of the collection of tourists' data through } \\
\text { questionnaires. } \\
\text { Web analysis }\end{array}$ \\
Techniques that use the analysis of comments, opinions, evaluations, \\
contents, etc. from online sources. \\
Techniques that consist of the continuous monitoring of tourists during \\
their trip through electronic devices. \\
Advertising & $\begin{array}{l}\text { Techniques consisting of the analysis of marketing campaigns made by } \\
\text { public and private institutions. } \\
\text { Techniques related to the data collection on entrance or admission } \\
\text { charges, packages, products, etc. sold by companies and tourist } \\
\text { attractions. } \\
\text { Techniques that can only identify the movement and behaviour of } \\
\text { visitors in limited spaces of a destination }\end{array}$ \\
\hline
\end{tabular}

Table 2. Techniques to track tourists from a demand-side approach

\begin{tabular}{ll}
\hline Category & Technique \\
\hline Survey & Traditional survey \\
& Travel diary \\
& Spatiotemporal movement diary \\
& Contents linked to a hashtag \\
& Geotagged contents in social media \\
Web analysis & Photographs uploaded to social media \\
& Travel fora contents \\
& Independent GPS devices \\
& Rental car GPS systems \\
& Other means of transport GPS \\
& Electronic devices GPS \\
Geolocation & Mobile phone GPS \\
& Mobile phone radiofrequencies \\
& Telephone company report \\
\hline
\end{tabular}


Table 3. Techniques to track tourists from a supply-side approach

\begin{tabular}{ll}
\hline Category & Technique \\
\hline \multirow{2}{*}{ Advertising } & Analysis of tourism promotion websites \\
& Analysis of fliers and similar sources \\
& Request of tourist attractions' lists to public administrations \\
& Report of customers' characteristics \\
Destination cards sold \\
Tourist packages sold by intermediaries \\
Reservation manager's bookings \\
Trip planner programmed visits \\
Traffic cameras and controls \\
Access points' controls \\
Surveillance cameras images \\
Free Wi-Fi access \\
Credit and debit card expenditure \\
Destination signage analysis \\
Tracing and direct observation of tourists
\end{tabular}

\section{Evolution of the use of tourist tracking techniques}

Once the techniques used to track tourists have been explained, it is worth analysing which techniques have been used in previous studies and which techniques have been most frequently used in current tourism research. To perform this task, a bibliometric analysis has been carried out to gather data of scientific contributions analysing tourist tracking within destinations. In Figure 1, it can be observed how the tourist tracking contributions have evolved from 1996 to 2018 . The figure shows three different stages in which tourist tracking techniques have been applied. A first stage took place at the end of the nineties, in which very few contributions related to this area were published. In fact, after this short period of time, it seems that relevant articles on tracking were not published for some years. From 2003 to 2007 certain researchers began to publish studies in this area again. Although there were more contributions published during these years than in the late 1990s, it seems that these studies were not able to encourage many researchers to specialize in this matter. However, in 2009 there was a boom in the number of articles dealing with the tracking of tourists. In addition, although the number of contributions made is reduced to a considerable extent in 2010, the data suggest that tourist tracking has become a growing field of study. In fact, since 2010 the number of contributions has continued growing steadily, reaching 15 published contributions indexed in Scopus in 2018, this being the year with the highest number of publications found in the series. The data regarding the number of contributions has an upward trend, so it can be expected to continue growing in the coming years. 


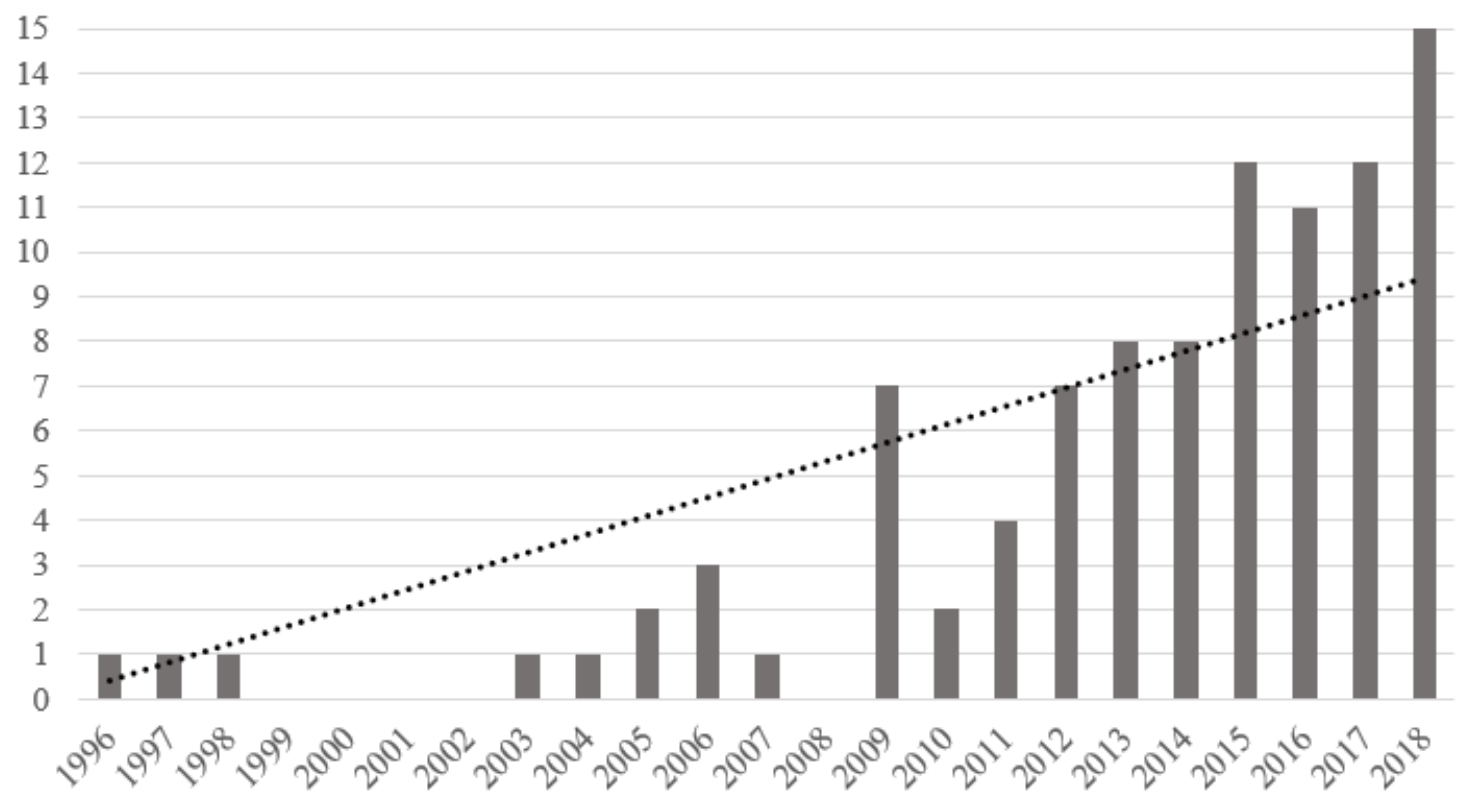

Figure 1. Evolution of the number of studies using tourist tracking techniques

Through the analysis carried out, we have reviewed the articles to identify which techniques are more frequently used by researchers to track tourists. This information is depicted in Table 4. In this figure, the frequency of use of each technique can be observed. The techniques based on geolocation of tourists are the most commonly used to identify the places visited, with this technique being used in $56 \%$ of the studies found in Scopus. After these techniques, the use of different types of surveys is the most common technique, representing $18 \%$ of total contributions. Techniques based on the study of specific places and the analysis of web pages have also been widely used in scientific research $(12 \%$ and $10 \%$ of studies, respectively). Techniques based on the analysis of the sales or reports of companies and the study of destination advertising have been used, in both cases, in only $2 \%$ of the studies.

Table 4. Frequency of use of each type of tourist tracking technique

\begin{tabular}{lll}
\hline Technique & Cases & Percentage \\
\hline Survey & $\mathbf{2 1}$ & $18.7 \%$ \\
Web analysis & 11 & $9.8 \%$ \\
Geolocation & 62 & $55.4 \%$ \\
Promotion & 2 & $1.8 \%$ \\
Sales & 2 & $1.8 \%$ \\
Specific spots & 14 & $12.5 \%$ \\
\hline Total & $\mathbf{1 1 2}$ & $\mathbf{1 0 0} \%$ \\
\hline
\end{tabular}

The bibliometric analysis identified not only the typology of techniques used, but also the specific techniques that had been used. Specifically, 16 techniques were identified. They have been used to a different extent in the 98 investigations that were found. In Table 5, it can be seen how the types of techniques used have changed and how the variety of techniques used to track the movement of visitors has also increased. Table 6 shows main statistics of the database used. 
Table 5. Evolution of the use of tourist tracking techniques

\begin{tabular}{|c|c|c|c|c|c|c|c|c|c|c|c|c|c|c|c|c|c|c|c|c|c|c|c|}
\hline & ڤั & ลิ & $\stackrel{\infty}{\Omega}$ & જે & : & : & ¿̊ & $\stackrel{n}{\stackrel{n}{N}}$ & 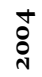 & $\stackrel{n}{\stackrel{n}{0}}$ & $\begin{array}{l}\text { : } \\
:\end{array}$ & 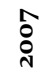 & 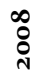 & $\stackrel{\overbrace{}}{\stackrel{\leftrightarrow}{0}}$ & 율 & 류 & $\frac{4}{3}$ & $\stackrel{n}{\stackrel{n}{*}}$ & ఫ্ণ & กิ & 율 & $\frac{1}{3}$ & $\stackrel{\infty}{\sigma}$ \\
\hline SURVEY & $\mathbf{1}$ & $\mathbf{1}$ & $\mathbf{1}$ & & & & & & & & $\mathbf{1}$ & & & 2 & $\mathbf{1}$ & & $\mathbf{1}$ & $\mathbf{1}$ & 2 & 3 & 4 & $\mathbf{1}$ & 2 \\
\hline Traditional survey & & & 1 & & & & & & & & & & & 2 & 1 & & & & 2 & 3 & 4 & 1 & 1 \\
\hline Street survey & 1 & 1 & & & & & & & & & 1 & & & & & & 1 & 1 & & & & & 1 \\
\hline WEB ANALYSIS & & & & & & & & & & & 1 & & & $\mathbf{1}$ & & & & 1 & 2 & 2 & & 3 & 1 \\
\hline Photographs & & & & & & & & & & & 1 & & & & & & & 1 & 2 & & & & \\
\hline Geotagged contents & & & & & & & & & & & & & & 1 & & & & & & 2 & & 2 & 1 \\
\hline Travel forums & & & & & & & & & & & & & & & & & & & & & & 1 & \\
\hline$\overline{\text { GEOLOCATION }}$ & & & & & & & & $\mathbf{1}$ & $\mathbf{1}$ & 2 & $\mathbf{1}$ & $\mathbf{1}$ & & 3 & $\mathbf{1}$ & 4 & 5 & 5 & 6 & 6 & 9 & 7 & 10 \\
\hline GPS device & & & & & & & & & & 1 & & & & 2 & 1 & 3 & 3 & 4 & 3 & 3 & 3 & 6 & 6 \\
\hline Mobile phone GPS & & & & & & & & 1 & & & 1 & & & 1 & & 1 & 2 & & 1 & 3 & 3 & & 2 \\
\hline Mobile radiofrequencies & & & & & & & & & 1 & 1 & & 1 & & & & & & 1 & 2 & & 3 & 1 & 2 \\
\hline ADVERTISING & & & & & & & & & & & & & & & & & & & & 1 & 1 & & \\
\hline Fliers analysis & & & & & & & & & & & & & & & & & & & & 1 & 1 & & \\
\hline SALES & & & & & & & & & & & & & & & & & & & & 1 & & & $\mathbf{1}$ \\
\hline Sales report & & & & & & & & & & & & & & & & & & & & 1 & & & 1 \\
\hline$\overline{\text { SPECIFIC SPOTS }}$ & $\mathbf{1}$ & $\mathbf{1}$ & & & & & & & & & & & & $\mathbf{1}$ & & & 1 & 2 & $\mathbf{1}$ & 1 & $\mathbf{1}$ & 2 & 3 \\
\hline Direct observation & 1 & 1 & & & & & & & & & & & & & & & & & 1 & & & & \\
\hline Access control & & & & & & & & & & & & & & 1 & & & & 2 & & 1 & 1 & & 1 \\
\hline Surveillance camera & & & & & & & & & & & & & & & & & & & & & & 1 & \\
\hline Free Wi-Fi access & & & & & & & & & & & & & & & & & 1 & & & & & 1 & 2 \\
\hline
\end{tabular}

Table 6. Main statistics of the database used.

\begin{tabular}{lllll}
\hline & Cases & Percentage & Mean $^{*}$ & Median $^{*}$ \\
\hline Traditional survey & 15 & $13.4 \%$ & 2013 & 2015 \\
Street survey & 6 & $5.4 \%$ & 2007 & 2006 \\
Photographs & 4 & $3.6 \%$ & 2012 & 2013 \\
Geotagged contents & 6 & $5.4 \%$ & 2015 & 2015 \\
Travel forums & 1 & $0.9 \%$ & 2017 & 2017 \\
GPS device & 35 & $31.3 \%$ & 2014 & 2014 \\
Mobile phone GPS & 15 & $13.4 \%$ & 2013 & 2014 \\
Mobile radiofrequencies & 12 & $10.7 \%$ & 2013 & 2014 \\
Fliers analysis & 2 & $1.8 \%$ & 2016 & 2015 \\
Sales report & 2 & $1.8 \%$ & 2017 & 2016 \\
Direct observation & 3 & $2.7 \%$ & 2002 & 1997 \\
Access control & 6 & $5.4 \%$ & 2014 & 2013 \\
Surveillance camera & $\mathbf{1}$ & $0.9 \%$ & $\mathbf{2 0 1 7}$ & $\mathbf{2 0 1 7}$ \\
Free Wi-Fi access & 4 & $3.5 \%$ & $\mathbf{2 0 1 6}$ & $\mathbf{2 0 1 7}$ \\
Total & $\mathbf{1 1 2}$ & $\mathbf{1 0 0} \%$ & $\mathbf{2 0 1 3}$ & $\mathbf{2 0 1 5}$ \\
\hline
\end{tabular}

${ }^{*}$ Calculated based on the year of publication of all studies using each technique.

In the early years, the most frequently used techniques were based on the direct observation of visitors and on surveying them to complement the information obtained. In the middle of the first decade of 2000, the techniques used began to diversify. Surveys continued being used, but data from web pages 
and geolocation devices also started to be analysed. At the end of this decade, the number of studies related to the tracking of visitors increased noticeably and, during the second decade of the millennium, it can be observed how these studies became popular, as shown in Figure 1. In addition, it is observed that after 2009, a multitude of studies have begun to be published in which visitors are tracked through independent GPS devices. This technique has been increasing its use to become the most commonly used tracking technique in tourism research in 2017 and 2018. This technique was also one of the most used ones from 2014 to 2016. However, during these years, there were other techniques that were frequently used by researchers, such as conducting traditional surveys or tracking the location of tourists through their mobile phone GPS. It can be observed in the table that the use of GPS devices has experienced a strong increase as a tracking technique after 2017. However, the rest of the techniques, although they have been used, have reduced their use.

In Table 5, the techniques found have been grouped according to the classification of techniques created for this study in order to see how their use has evolved. Techniques linked to the geolocation of tourists are those that have experienced the greatest growth since their appearance, increasing almost continuously during all the years studied. Techniques focused on analysing specific places also seem to have increased their use throughout the period studied, although their usage shows to be lower than the use of geolocation-based techniques. The collection of data from surveys has also increased, but seems to have reduced its usage in the final years of the series. The analysis of web pages presents a discontinuous evolution and latest available data seem to indicate that its use is currently declining. Advertising and sales techniques have been used in few studies in all the period analysed, so it is difficult to estimate how their usage will evolve in future years.

When carrying out the literature review to determine which tracking techniques have been used by researchers to analyse how tourists move, it was observed that more than a single technique was used to obtain the desired data. In fact, Kádár (2014) and Raun et al. (2016) stated that all techniques have limitations and, therefore, the combination of them is key to complement the deficiencies of certain techniques with the data provided by others. Table 7 shows the different classifications of the techniques and indicates, for each case, the frequency they tend to be used independently and in combination with techniques from other categories.

Table 7. Individual vs combined use of tourist tracking techniques

\begin{tabular}{lcccc}
\cline { 2 - 5 } Category & \multicolumn{2}{c}{ Number of studies } & \multicolumn{2}{c}{ Percentage } \\
\cline { 2 - 5 } & Individual use & Combined & Individual use & Combined \\
\hline Survey & 8 & 13 & $38.1 \%$ & $61.9 \%$ \\
Web analysis & 11 & 0 & $100 \%$ & $0 \%$ \\
Geolocation & 51 & 11 & $82.3 \%$ & $17.7 \%$ \\
Advertising & 2 & 0 & $100 \%$ & $0 \%$ \\
Sales & 2 & 0 & $100 \%$ & $0 \%$ \\
Specific spots & 10 & 4 & $71.4 \%$ & $28.6 \%$ \\
\hline
\end{tabular}

From the data reflected in the table, it can be noted that techniques included in the "Web analysis", "Advertising" and "Sales" categories do not tend to be used in conjunction with other tracking techniques. Despite this, it should be noted that two studies were identified in which data mining had been used to obtain the data. In both cases, the studies have been included as part of the "Web analysis" category and have not been considered as studies combining techniques. This is because both studies extracted web data published by tourists, so the data obtained in these studies refer to contents in social media, travel forums and online communities. As all these techniques refer to "Web analysis" category, 
it cannot be stated that techniques from other categories tend to be used with "Web analysis" techniques. The data also indicate that techniques grouped into the "Surveys", "Geolocation" and "Specific spots" categories have been used in combination with other techniques. According to the data, techniques based on conducting surveys have a high tendency of being used in combination with other techniques, limiting their individual usage to approximately $38 \%$ of cases. However, techniques included in "Geolocation" and "Specific locations" categories, although used in combination with other techniques, have a greater tendency of being used individually.

Through this analysis, it has not only been possible to identify which types of tracking techniques are more likely to be used in combination with other techniques, but we have also analysed which techniques are more frequently used in combination with others. In order to graphically display these data, Table 8 is presented. It only shows which techniques have been used in combination with others and those techniques that have been used in conjunction with them.

Table 8. Combinations of tourist tracking techniques in tourism research

\begin{tabular}{llll}
\hline Technique & Combinations & $\begin{array}{l}\text { Number of } \\
\text { studies }\end{array}$ & Percentage \\
\hline \multirow{2}{*}{ Traditional survey } & GPS device & $\mathbf{1 0}$ & $76.9 \%$ \\
& Mobile GPS & $\mathbf{2}$ & $\mathbf{1 5 . 4} \%$ \\
Street survey & Access controls & $\mathbf{1}$ & $7.7 \%$ \\
GPS device & Direct observation & $\mathbf{2}$ & $\mathbf{1 0 0} \%$ \\
& Traditional survey & $\mathbf{1 0}$ & $90.9 \%$ \\
Mobile GPS & Mobile GPS & $\mathbf{1}$ & $9.1 \%$ \\
& Traditional survey & $\mathbf{2}$ & $50.0 \%$ \\
Direct observation & GPS device & $\mathbf{1}$ & $\mathbf{2 5 . 0} \%$ \\
\multirow{2}{*}{ Access controls } & Access controls & $\mathbf{1}$ & $\mathbf{2 5 . 0} \%$ \\
& Street survey & $\mathbf{2}$ & $100 \%$ \\
Wi-Fi & Traditional survey & $\mathbf{1}$ & $33.3 \%$ \\
\hline
\end{tabular}

As can be seen in Table 8, three of the seven techniques identified have been used only in conjunction with a single technique. In the case of street surveys and direct observation, these techniques are usually combined. These techniques were the most frequently used by researchers in the oldest studies from which data could be obtained. In these studies, tourists were followed in certain places of the destination to gather data on their movements, and they were surveyed afterwards to collect data regarding their socioeconomic and motivational characteristics. Data gathered through free Wi-Fi connections are commonly combined with data collected by access controls. When connecting to public Wi-Fi networks, the data linked to tourists' devices are accessible to the managers of these networks and, through access controls, it can be known if tourists have accessed certain attractions and the amount of time spent within them.

Traditional surveys carried out at the end of the tourists' trips are usually combined with GPS tracking devices given by researchers. This shows the places tourists have visited during their trip and, through the surveys, researchers can collect their socioeconomic characteristics and their motivations to visit certain tourist attractions. Similar results can be obtained by combining surveys with the records of access controls or mobile phone GPS data that enables researchers to identify the places visited by 
tourists. Tracking through GPS devices has mostly been combined with surveys, but also with the data of tourists' mobile phone GPS. The data provided by GPS tracking or by a mobile phone GPS will tend to be similar, so using them together would not significantly increase the amount of information obtained. In fact, they have only been used together in one study in which the aim was to compare which technique was more suitable for collecting data from tourists. Mobile phone GPS data have been mainly combined with surveys and GPS devices, as already mentioned. However, they have also been compared with data provided by access controls, identifying the places which tourists have accessed, not just if they have been in the vicinity of these places.

\section{Techniques: advantages and disadvantages to consider}

As has been shown, the techniques described have been commonly combined. Doing this, researchers can achieve a larger sample, gather more information about more variables and test the data collected. Previous studies have already pointed out that combining different techniques is a key aspect of using tourist tracking techniques to understand tourists' movements and behaviour within destinations (Raun et al., 2016). The problem arises when researchers must choose which techniques to use. The existence of so many techniques is justified as all of them present certain limitations that prevent them from being used in all kinds of study (Shoval \& Isaacson, 2010). In fact, the studies of Hardy, Aryal, \& Wells (2019) and McKercher, Hardy, \& Aryal (2019) used two tracking techniques to compare the data gathered and they conclude that both are required to get as much information as possible. Therefore, researchers need to properly consider the advantages and disadvantages of each technique, before deciding which one to use or which ones to combine in order to achieve the aims of their research (Raun et al., 2016). In our research, six key aspects have been found that should be considered before choosing a certain technique. The six aspects are: an obtainable sample using the technique; the monetary and time investment for its application; the degree of dependence on third parties to obtain the data; the type and number of variables gathered; the quality and accuracy of the data obtained; and the ethical and data protection restrictions linked to the use of the tracking technique.

\section{Obtainable sample}

The number of tourists or places that can be analysed is one of the aspects that must be considered when choosing the techniques to be used. Certain techniques allow a large amount of information to be obtained from a single tourist but the collection of data cannot be done simultaneously for several tourists (Keul \& Kühberger, 1997). Thus, gathering information becomes harder and it limits the sample researchers will eventually use to carry out their studies. This difficulty could be solved by using enough time to obtain a sample that is considered significant for the study. However, this could delay the publication of the results of the study, which could lead to a loss of relevance of the conclusions. Other techniques, however, make it easier to obtain a larger sample (de Oliveira \& Porto, 2016). Having statistically significant samples is useful to justify the validity of the research carried out. In addition, having enough data allows publishing information related to certain segments without it being possible for third parties to distinguish specific individuals.

Traditional surveys can gather information regarding a significant sample of individuals, since they are usually carried out in places of frequent transit of tourists, such as airports (Eurostat, 2014). However, the rest of the techniques included in the "Survey" category present difficulties to study a large number of individuals. Street surveys are carried out at specific locations and times, so they only focus on certain tourists. Travel diaries should be made by the same tourists at the end of each day of stay, so they require choosing specific individuals to study and any kind of error or missing value could derive in the nonconsideration of all data regarding an individual (Zoltan \& McKercher, 2015). Spatiotemporal movement diaries require a large amount of time to be given by tourists, as they must state which places have been 
visited and the timing of the visits at the end of the trip. In addition, these kinds of surveys require tourists to voluntarily participate in the research, as researchers need them to give as sincere and detailed responses as possible (Zoltan \& McKercher, 2015).

Techniques classified within "Advertising" category are characterized by being able to provide information relative to a wide sample of places. Destinations usually have an abundant number of brochures. In the same way, public administrations usually have a detailed record in which they list the main attractions of a destination. In addition, they are likely to promote attractions in official tourism promotion portals to capture more tourists (Shoval \& Isaacson, 2010). The same applies to those techniques categorized as "Sales", because the number of tourists received by the places analysed can be accurately known. These techniques can also be applied to all those places that require an entrance for their access. The exception would be the analysis of destination cards, since the acquisition of one of them does not guarantee that the tourist has visited all the places it contains, which makes it difficult to know the behaviour of the individuals studied (Shoval \& Isaacson, 2010). The use of the techniques included in the "Web analysis" category also allows a large sample to be obtained, given the number of users who currently use social media (Kádár, 2014).

Certain techniques are only valid for the study of certain places or segments. Through their use, specific tourists or places can be analysed, as happens with techniques based on the use of geolocation devices or the analysis of specific sites in a destination. Therefore, data collected through these techniques cannot gather information from all the agents that may be involved in the analysis (Raun et al., 2016). This can considerably reduce the statistical population that will be analysed and limits the sample from which the information will be obtained which, in turn, reduces the reliability of the results.

\section{Application cost}

Although certain techniques allow a greater amount of data to be obtained more easily, it is possible to use any of the techniques mentioned to obtain the desired data sample. However, what will determine the size of the sample or the information obtained by a specific technique is the investment made to carry it out. When talking about investment, we are referring to monetary and temporal investments. Certain techniques may have a low monetary cost but require, instead, a large investment of time to obtain the sample required for the research. Thornton et al. (1997) pointed out that this is the case of direct observation of tourists, as the researcher is usually responsible for applying the technique, but the consumption of time required for this is enormous. It is worth mentioning that time consumption can be reduced by increasing the number of participants involved in the study. However, this usually increases the monetary cost of the research.

On the other hand, certain techniques do not require a high amount of time. However, obtaining the information represents a high monetary cost for researchers (Eurostat, 2014). Certain mobile phone companies have begun to sell information regarding the movements made by tourists within destinations. Obtaining this type of data would not entail a significant time investment, since data have already been collected by telephone companies (Dattilo et al., 2016; Seynaeve \& Demunter, 2016). However, accessing these data would imply an important monetary investment (Eurostat, 2014). In the same way, it must be considered that the person in charge of the data collection is a factor that affects the costs incurred when applying the technique. By contrast, public statistical agencies perform the data collection function with the aim of publishing data and making them freely accessible. In this case, access to this information does not require a high monetary or time investment by the researcher. However, if the researcher is the one in charge of gathering data from tourists, the monetary or time cost that could be incurred to collect these data could be quite significant (Eurostat, 2014). 
It should also be considered that certain techniques require a greater investment of time than others in order to process the information once it has been collected. The collection of data related to the trips made by visitors through GPS devices, web pages or the processing of qualitative information obtained through interviews require slower and more complex processing. Data obtained by these techniques are not always imported directly into a spreadsheet and are often difficult to quantify, which makes it difficult to extract results from them.

On the other hand, there are other techniques that can be applied by making a small monetary investment and do not require high time consumption while applying and processing the information. Techniques based on obtaining data from public administrations and companies usually fit this description. Some examples would be gathering data from public surveys, companies' client records when companies are interested in carrying out the study or the analysis of official lists of tourist attractions. By contrast, certain techniques require a high monetary cost of application and, in turn, a high amount of time, which discourages researchers from using them. Such is the case of the installation of video surveillance cameras in certain spaces of a destination, the direct observation of tourists' movements or the delivery of independent GPS devices to tourists.

\section{Third party dependence}

Companies and other institutions may have information regarding the number of products, services or activities sold to tourists during a given period. Through these data, it is possible to find out the number of users who have acquired a certain type of product, as well as the places visited through the number of packages sold by intermediaries, etc. (Shoval \& Isaacson, 2010). The possibility of purchasing through the Internet electronic records of the sales made. However, needing the support of an external institution to obtain information about tourists generates a series of problems and limitations when certain techniques are applied by researchers.

First, the study must be supported by a third party willing to provide access to the information needed. Establishing contact with certain organizations requires a significant amount of time, as the reason to have the information must be explained and researchers must wait for the response of the organizations. Moreover, researchers must wait until the required information is eventually received. In addition, possible meetings and intermediate agreements should be considered to specify what information is desired and which data will be granted in the end. It should also be considered that the justification of the data requested may not convince the organization and, thus, it could finally decide not to cede the data required.

Secondly, it must be considered that, even though the desired information is obtained, institutions that have granted access to it may request a data transfer agreement to be signed. Thus, certain conditions of the concession may prevent the publication of the results obtained. Occasionally, this type of information is even limited by data protection laws (Renenger, 2001), preventing either the institutions from transferring the data or the data being published by them or third parties. In addition, each institution can have different types of information, which limits the standardization of the data obtained from different sources. On the other hand, access to information can be easier if it is compiled by some type of public organization, such as statistical institutes or certain public administrations.

A final aspect to consider is the knowledge of the methodology used by the institution to collect the data. When aiming to analyse the places visited by tourists, it is necessary to know if organizations are differentiating between those visitors to a place who are tourists and those who are not. In the case of data collected by companies, data are likely to only refer to their clients, without making a distinction 
between tourists and residents. However, public agencies are more likely to publish differentiated and more detailed information. Along the same lines, it is more complicated to find private organizations that have detailed methodological reports that explain how the information has been collected and processed. This could lead to a series of problems for researchers to be able to justify the reliability of the study carried out.

As conducting surveys is the most commonly used technique to collect data from tourists (Eurostat, 2014), this function is usually performed by public statistical institutes that publish the data collected and a methodological document explaining how the collection and processing of data have been conducted. Therefore, the use of these data is easier for researchers. However, statistical institutes tend to collect information only through limited types of surveys, such as traditional surveys or, occasionally, street surveys. Travel diaries or spatiotemporal movement diaries are usually applied by researchers themselves when interested in specifically studying the movements of tourists (Liu et al., 2017; Thornton et al., 1997).

Techniques based on the analysis of places promoted have the advantage of analysing easily accessible information made by public and private institutions. The same applies to the analysis of social media and information shared by visitors through the Internet, as researchers can search and access it with relative ease (Shoval \& Isaacson, 2010). Researchers can also convince tourists to voluntarily participate in studies where GPS tracking is applied, so accessing the data collected presents no limitations (East et al., 2017). The request of information to public administrations implies waiting for the information and the uncertainty of its quality. However, accessing this data should be simple as it is public property information. On the other hand, when dealing with private agents, their agreement is necessary to receive data about products and services sold, to access their databases, etc. In addition, access to some of these data may require prior payment, as is the case with telephone companies (Shoval \& Isaacson, 2010).

\section{Amount of data gathered}

Although the general objective of tracking tourists is the study of the places that tourists visit during their trips, there are other data that are relevant for analysis. Although all techniques listed allow the identification of places that have received a certain influx of visitors, the additional information these techniques can provide must be considered. Therefore, when choosing techniques to apply, researchers should know what additional information they may want to gather in their studies. This may condition the choice of a certain technique instead of another (Raun et al., 2016).

Among others, knowing the socioeconomic profile of a tourist can be used to link data to tourists' characteristics with the places they have visited. Some of the characteristics most commonly analysed are nationality, age, gender, incomes or educational level (Padrón-Ávila \& Hernández-Martín, 2019b). However, there are other characteristics that could lead to interesting results, such as knowing why tourists have visited the destination, their motivations for travelling, how they assess the trip or the attractions visited, among others (Padrón-Ávila \& Hernández-Martín, 2019a). There are even other variables that can greatly condition the places visited by tourists during the trip, such as having previously visited the destination, purchasing all-inclusive packages from tour operators or travel agencies, travelling with a certain travel group, etc. (Thornton et al., 1997). In addition, it is even possible to link tourists' profiles to the total expenditure made during the trip, as well as the expenses incurred when visiting a specific place. This allows a relationship to be established between the visit to a place and the total expense incurred during the trip. 
Moreover, while studying how tourists move, researchers could be interested in knowing how they have visited the places visited. Among others, some interesting topics to be analysed would be: knowing how tourists connect to the places visited; the order in which they have made these connections; the time they have spent at them; the time at which a certain place receives the greatest influx of visitors, etc. (McKercher \& Lau, 2008; McKercher \& Zoltan, 2014; Shoval et al., 2018). In addition, certain techniques can even ascertain how the number of days spent at the destination are linked to the number of places visited during the trip and with the itineraries made. All techniques are limited to obtaining certain information, which may require the use of different techniques to gather all the data required (Raun et al., 2016). It should also be considered that certain techniques present a higher degree of flexibility than others to gather data. Thus, certain techniques can be adapted to the needs of the study and obtain certain information depending on the needs of the research. Those techniques that are more flexible and allow the greatest amount of data to be obtained will tend to be the most convenient in studies (Shoval \& Isaacson, 2007).

Surveys allow the collection of a wide variety of information because questions can be adapted to the information needs of the research. However, collecting accurate data regarding the places that have been visited and the itinerary through a survey is a complex task. Traditional surveys cannot collect all the places that can be visited by tourists. However, Leones, Colby, \& Crandall (1998) indicate that they are appropriate when trying to obtain data related to the expenses incurred by visitors, given the limitations of other techniques to collect this kind of information. But even the data relating to expenses incurred during the trip are limited, since tourists must remember the exact sum of money used during their trips. For this reason, street surveys, travel diaries and spatiotemporal movement diaries tend to be more appropriate techniques for collecting this type of information.

Techniques categorized in "Advertisement" only identify places where products or services are sold to visitors and, on certain occasions, the markets to which these products are oriented. However, it does not facilitate the identification of itineraries (Shoval \& Isaacson, 2010). "Sales" techniques do not gather these data either, although they do provide more data regarding tourists' characteristics based on the information that is compiled by the companies or organizations collecting the data. Counting the number of tickets to attractions or destination cards sold is very useful to know the exact number of tourists entering a place. Moreover, client reports also allow show the characteristics of the tourists of these places. Despite this, these techniques are only applicable in those places where control systems to enter them are used (Shoval \& Isaacson, 2010).

The analysis of web pages, the use of geolocation devices or the study of specific places identify which places are visited, the itineraries that are followed, the satisfaction with the trip and the places visited, the sociodemographic characteristics of tourists and others. However, information such as the expenses incurred during the trip are not always possible to obtain through these techniques (Shoval \& Isaacson, 2010).

Quality and accuracy of the data

Although certain techniques can provide information about many different variables, the data obtained could be imprecise or even erroneous. For this reason, certain techniques are sometimes chosen instead of others because they can gather more data. Problems arising from the need for certain data may not directly be linked to the technique used to gather data, but with the answers and information provided by tourists. Certain personal data are less likely to be provided by tourists, such as annual income, political and religious affiliation or sexual orientation. However, these variables may be relevant to understand tourists' behaviour and their mobility patterns (Visser, 2014; Waitt \& Markwell, 2006). In 
addition, there is certain information that may be unremembered or ignored by visitors. For example, they may forget some of the places they have visited or may not know how some of these places are named.

For this reason, techniques that depend on the responses provided by tourists, such as surveys, are more likely to present errors that could be difficult to detect (Shoval \& Isaacson, 2007). Tourists do not tend to remember the precise amount of money spent during the trips and the places where they have spent this money. Unless surveys are conducted just after the expense, this type of information will tend to be forgotten or confused (Shoval \& Isaacson, 2007). However, other techniques, such as geolocation tracking devices, can provide more solid information that the researcher can objectively verify. All this also explains why if a certain tourist is tracked using two different methods, the data that could be obtained from them could be contrary. Some researchers have also highlighted that how the awareness of being tracked can affect the mobility patterns of tourists has not been studied (Shoval \& Isaacson, 2007). So even those techniques that do not depend on the subjectivity of the tourists' responses can provide partially erroneous information if tourists behave in a such a way as to deceive the techniques used.

Contents shared on web pages, despite being able to help identify the places visited and the itinerary carried out, present certain analytical problems. When collecting data, the time the contents have been uploaded to the platform by users can be determined, however it cannot be verified if the activity that is reflected in them has taken place at the precise moment when contents were uploaded (Shoval \& Isaacson, 2010). In addition, depending on the social media analysed, data obtained varies. Moreover, the analysis of multiple social media as sources of information can cause double counting of a single visit made by the same tourists if they have profiles in various social media (Shoval \& Isaacson, 2007). Similarly, an analysis of advertising campaigns identifies which places are being promoted among tourists, but not if tourists actually go to these places or if enterprises are attracting the segments to which promotional campaigns are oriented. By contrast, sales records provide information of high quality and reliability based on real records of clients who have visited certain places. In the case of sales records, the information collected is used through the accounting of tickets sold, as well as possible surveys that may have been made to a sample of users.

\section{Ethical dilemma and data protection restrictions}

Certain tracking techniques present moral and ethical dilemmas that must be considered if researchers intend to use them in their studies. Most of these problems are related to the way in which certain procedures may be contrary to visitors' rights to privacy (Shoval \& Isaacson, 2007). In fact, legal systems are not fully prepared to handle this reality and the problems associated with it yet (Renenger, 2001), so the information collected can be used for various purposes that could be considered unethical. On the one hand, tracking people can be a violation of their right to privacy. In addition, the current data protection laws establish limits to the use of the data that could be obtained (Renenger, 2001). Therefore, the consent of the participants would be necessary in the study to use their data. On the other hand, some researchers have pointed out that intimacy abusing is not such a major problem to consider, since tracked people are supervised for a limited and defined period of time (Shoval \& Isaacson, 2007).

Regarding the legal framework that would affect the possible implementation of this type of technique, several regulations and agreements on an international scale could condition the application of certain tracking techniques, as well as existing restrictions at national or subnational scales. The Organization of the United Nations (UN) and the Organization for Economic Cooperation and Development (OECD) 
are the main international organizations that have established guidelines in this regard. Within the framework of the European Union (EU), the Charter of Fundamental Rights of the European Union (Charter of fundamental rights of the European Union, 2000) and the Treaty of Lisbon (Treaty of Lisbon, 2007) agree on the regulation of the legal protection of EU citizens' data.

Article 12 of the Universal Declaration of Human Rights of the UN (United Nations, 1948) establishes that every person must be protected against the interference of third parties in their private life, family, home and correspondence. This seems to indicate that this body intends to limit the collection of personal information of a specific individual by third parties. However, in the Guidelines for the Regulation of Computerized Personal Data Files, the UN allows the collection of personal data (Guidelines for the Regulation of Computerized Personal Data Files, 1990). Despite this, it proposes the establishment of a series of limitations and guarantees that ensure the privacy of personal data and the agreement of the people studied to collect data related to them. In addition, it prohibits the collection of certain information, such as data concerning religious beliefs, political preferences, ethnic origin, skin colour or sexual orientation.

In the case of the OECD, the Guidelines on the Protection of Privacy and the Transborder Flows of Personal Data includes a principle of limitation of the collection of personal data (OECD Guidelines on the Protection of Privacy and Transborder Flows of Personal Data, 1980). This principle establishes that people should be aware that their data are being collected and the purpose for which the data are being used. It also states that the aim of the data collection cannot vary without the authorization of the people from whom the information has been collected. Years after writing this document, the Ministerial Declaration on the Protection of Privacy on Global Networks was signed, which ratifies the recommendations contained in the document prepared in 1980 and undertakes to launch legal actions to ensure its compliance. It also promotes the exchange of information among member countries (Ministerial Declaration on the Protection of Privacy on Global Networks, 1998).

The EU has also started to regulate practices that violate the right to privacy of EU citizens. Article 8 of the Charter of Fundamental Rights of the European Union (Charter of fundamental rights of the European Union, 200o) specifies that personal data must be used for specific purposes that must be previously approved by the person from whom data are being collected. In addition, the Treaty of Lisbon (Treaty of Lisbon, 2007) ratifies the agreement reached through the Charter of Fundamental Rights of the European Union, although it adds some modifications to facilitate the exchange of data among EU countries, especially in judicial matters.

Certain tracking techniques seem to be more susceptible to violating the principles contained in the regulations quoted than others. For example, data collected by companies through sales or through clients' records are especially likely to violate certain regulations and international agreements if they are disclosed. This is because clients of these companies may not know that their data are being collected or what the purpose of the data collection is. The use of surveys on tourists can be carried out but must be carried out in accordance with the specific regulations that regulate them, which may not allow publishing information regarding the trips made by a tourist. In addition, certain regulations may increase the restrictions when it comes to applying certain techniques, such as using surveillance cameras or access controls in certain spaces, to gather data from tourists who are not informed that they will be supervised for this purpose before entering certain spaces. All these limitations vary depending on the place where techniques are applied and the legislation of these areas. Thus, researchers need to consider all the existing legal limitations when deciding which tracking techniques to use and which data can be gathered with them. 


\section{Summary of strengths and weaknesses of tracking techniques}

To facilitate the choice of the tracking technique to apply to future researchers, the main strengths and weaknesses of the tracking techniques identified have been summarized in Table 8 . As can be seen in the table, techniques composing the categories created usually share some (or even all) the strengths and weaknesses analysed.

Table 8. Comparison of strengths and weaknesses of tourist tracking techniques

\begin{tabular}{|c|c|c|}
\hline Technique & Main strengths & Main weaknesses \\
\hline Traditional survey & Big sample, much information & $\begin{array}{l}\text { Difficult to analyse all places visited and } \\
\text { itineraries, time-consuming }\end{array}$ \\
\hline Street survey & Many variables, precise data & $\begin{array}{l}\text { Difficult to analyse itineraries, expensive, time- } \\
\text { consuming }\end{array}$ \\
\hline Travel diary & Many variables, precise data & Difficult to analyse itineraries, time-consuming \\
\hline $\begin{array}{l}\text { Spatiotemporal movement } \\
\text { diary }\end{array}$ & Much information & $\begin{array}{l}\text { Difficult to analyse all places visited and } \\
\text { itineraries, time-consuming }\end{array}$ \\
\hline Contents linked to a hashtag & Huge sample & $\begin{array}{l}\text { Imprecise, dependence of a webpage, limited } \\
\text { variables }\end{array}$ \\
\hline $\begin{array}{l}\text { Geotagged contents in social } \\
\text { media }\end{array}$ & Huge sample & $\begin{array}{l}\text { Imprecise, dependence of a webpage, limited } \\
\text { variables }\end{array}$ \\
\hline $\begin{array}{l}\text { Photographs uploaded to } \\
\text { social media }\end{array}$ & Huge sample & $\begin{array}{l}\text { Imprecise, dependence of a webpage, limited } \\
\text { variables }\end{array}$ \\
\hline Travel fora contents & Huge sample & $\begin{array}{l}\text { Imprecise, dependence of a webpage, limited } \\
\text { variables }\end{array}$ \\
\hline Independent GPS devices & $\begin{array}{l}\text { Good to study all places visited and } \\
\text { itineraries, much information, very precise } \\
\text { data }\end{array}$ & Small sample, expensive, time-consuming \\
\hline Rental car GPS systems & $\begin{array}{l}\text { Good to study all places visited and } \\
\text { itineraries, big sample, much information, } \\
\text { very precise data, data already processed }\end{array}$ & Dependence of a company, ethical issues \\
\hline $\begin{array}{l}\text { Other means of transport } \\
\text { GPS }\end{array}$ & $\begin{array}{l}\text { Good to study all places visited and } \\
\text { itineraries, big sample, much information, } \\
\text { very precise data, data already processed }\end{array}$ & Dependence of a company, ethical issues \\
\hline Electronic devices GPS & $\begin{array}{l}\text { Good to study all places visited and } \\
\text { itineraries, big sample, much information, } \\
\text { very precise data, data already processed } \\
\text { Good to study all places visited and }\end{array}$ & Dependence of a company, ethical issues \\
\hline Mobile phone GPS & $\begin{array}{l}\text { itineraries, much information, very precise } \\
\text { data }\end{array}$ & Small sample, time-consuming \\
\hline $\begin{array}{l}\text { Mobile phone } \\
\text { radiofrequencies }\end{array}$ & Huge sample, data already processed & Expensive, dependence of a company, imprecise \\
\hline Telephone company report & $\begin{array}{l}\text { Good to study all places visited and } \\
\text { itineraries, huge sample, much } \\
\text { information, very precise data, data already } \\
\text { processed }\end{array}$ & $\begin{array}{l}\text { Expensive, dependence of a company, ethical } \\
\text { issues }\end{array}$ \\
\hline $\begin{array}{l}\text { Analysis of tourism } \\
\text { promotion websites }\end{array}$ & Precise data, free and fast access & $\begin{array}{l}\text { Difficult to analyse all places visited and } \\
\text { itineraries, small sample, few information, } \\
\text { dependence of a third party }\end{array}$ \\
\hline $\begin{array}{l}\text { Analysis of fliers and similar } \\
\text { sources }\end{array}$ & Precise data, free and fast access & $\begin{array}{l}\text { Difficult to analyse all places visited and } \\
\text { itineraries, small sample, few information, } \\
\text { dependence of a third party }\end{array}$ \\
\hline $\begin{array}{l}\text { Request of tourist } \\
\text { attractions' lists to public } \\
\text { administrations }\end{array}$ & Precise data, data already processed & $\begin{array}{l}\text { Difficult to analyse all places visited and } \\
\text { itineraries, small sample, few information, } \\
\text { dependence of a third party }\end{array}$ \\
\hline $\begin{array}{l}\text { Entries sold by tourist } \\
\text { attractions }\end{array}$ & Precise data, data already processed & $\begin{array}{l}\text { Difficult to analyse all places visited and } \\
\text { itineraries, small sample, few information, } \\
\text { dependence of a third party }\end{array}$ \\
\hline
\end{tabular}


Report of customers'

characteristics

Destination cards sold

Tourist packages sold by intermediaries

Reservation manager's

bookings

Trip planner programmed visits

Traffic cameras and controls

Access points' controls

Surveillance cameras images

Free Wi-Fi access

Credit and debit card expenditure

Destination signage analysis

Tracing and direct

observation of tourists
Much information, precise data, data already processed

Big sample, precise data

Big sample, much information, precise data

Precise data

None

Good to study itineraries, big sample, precise data

Big sample, precise data

Big sample

Huge sample, precise information, data already processed

Good to study itineraries, huge sample, much information, precise information

None

Good to study all places visited and itineraries
Difficult to analyse all places visited and itineraries, small sample, dependence of a third party

Difficult to analyse itineraries, few information, dependence of a third party

Dependence of a third party, ethical issues

Difficult to analyse all places visited and itineraries, small sample, dependence of a third party, ethical issues

Difficult to analyse all places visited and itineraries, small sample, few information, dependence of a third party, ethical issues Difficult to analyse all places visited, timeconsuming, few information, ethical issues Difficult to analyse all places visited and itineraries, few information

Time-consuming, few information, ethical issues

Difficult to analyse all places visited and itineraries, few information, dependence of a third party

Difficult to analyse all places visited, dependence of a company, ethical issues Difficult to analyse all places visited, few information, time-consuming

Small sample, few information, ethical issues

\section{Discussion}

When carrying out the literature review, 31 possible tourists tracking techniques were identified. However, the results of the bibliometric analysis applied in this study points to the actual use of just 14 techniques. As Scopus was the unique database used to perform the analysis, contributions indexed in other databases might have been ignored. The use of Web of Science, Google Scholar or similar scientific databases could have brought other relevant publications into the analysis. Nevertheless, as the literature review carried out did not only focus on analysing those tracking techniques previously applied but also those techniques suggested by past studies, certain techniques might have been suggested but not actually applied. For example, travel diaries were pointed by Liu et al. (2017) as a tracking technique, but they do not use it. In addition, as the unique search terms used were tourist and tracking, those contributions containing other search terms have been ignored. Thereby, even if Liu et al. (2017) point to studies using travel diaries, these studies did not contain the aforementioned terms in their title, abstract or keywords, so they were not identified.

Kádár (2014) and Raun et al. (2016) state that there are not perfect tracking techniques, what can be verified through the explanation of the advantages and disadvantages conditioning the choice of the technique to apply. Moreover, these authors point to combining tracking techniques as key to gather the data required to carry out different studies. Our findings support this claim as they point that combining tracking techniques is frequent in tourism research. The results also show the most frequently combined techniques. However, Kádár (2014) and Raun et al. (2016) point to all techniques having strengths or weaknesses to justify the existence of so many different tracking techniques and the apparition of new ones. Despite this, the study identified several techniques that had never been used and certain studies even discouraged future researchers to use the technique employed. For example, Keul \& Kühberger (1997) do not recommend the direct observation and follow-up of tourists for being very time-consuming and for disturbing the tourists tracked. In addition, analysing programmed visits 
recorded by trip planners might allow knowing tourists' intentions but not their actual behaviour and it requires having the support of the company managing the platform to access data. In the same lines, studying destination signage might help identifying most usual mobility patterns but not tourists' true behaviour.

\section{Conclusions}

Despite several studies analysing tourists' mobility and behaviour using tourist tracking techniques, there are no previous papers gathering information about these techniques in order to let researchers know how these techniques could be applied. Moreover, there are only a few studies that have been carried out to compare the data that can be obtained using a small number of tracking techniques. Thus, more theoretical studies are required, as they help understand how these techniques work and the problems researchers find when applying them. In fact, the main aim of this study is to help researchers choose the right tracking techniques to apply in their studies. To do so, this study has attempted to summarize the characteristics of the current tourist tracking techniques used by researchers in studies on tourist mobility and behaviour. In order to achieve this, a literature review has been carried out to understand which techniques have been used and how they work. After this, a bibliometric analysis has highlighted the evolution of the use of these techniques, which has also allowed an estimation of their future evolution. The analysis has also been complemented with another literature review to analyse pros and cons of different tourist tracking techniques.

The literature review has identified the existence of 31 techniques to track tourists' movements. These techniques focus on two different elements as some of them analyse the movements made by tourists to identify which places are visited (techniques from a demand-side approach), while others study some places in the destination to ascertain the characteristics of those tourists visiting them (techniques from a supply-side approach). Moreover, as all techniques share common characteristics with others, they have been grouped into six different categories. These categories have also been divided into those ones used from a demand-side approach and those used form a supply-side approach. On the one hand, demand-side techniques are based on surveying tourists, analysing online contents posted by previous tourists, and using geolocation devices to track tourists' movements. On the other hand, supply-side techniques are those analysing tourism advertisement campaigns to know which places are promoted, studying sales records of tourist attractions, and analysing the actions taking place in specific sites of tourism destinations.

When choosing the techniques to use, researchers should consider which the mostly used techniques are in order to increase their probabilities of writing papers that journals will be more likely to be published. The performance of a bibliometric analysis has shown that currently the most used techniques to track tourists are those techniques grouped under the "Geolocation" category. Techniques based on surveying tourists and analysing specific sites in destinations are also used to track tourists' movements. Certain techniques, such as the direct observation of tourists or conducting street surveys, have been used in the past but their usage is currently declining. However, other techniques, such as tracking tourists' position through GPS devices, their mobile phones or the analysis of contents posted on web pages, are expected to be used in a larger numbers of studies in coming years. Consequently, the number of studies based on the use of tourist tracking techniques in general is expected to grow during next years.

In spite of the importance of using current research tracking techniques, researchers should also consider the advantages and disadvantages of the possible techniques to use. These pros and cons are important, as they may restrict the use of certain techniques or make other techniques more suitable 
to carry out some studies. Through a literature review, six key aspects to consider before choosing a tracking technique have been found. These considerations are: the sample that can be obtained, the monetary and temporal cost involved in the application of the technique, the dependence of third parties, the number of variables gathered with the technique, the quality and accuracy of the data gathered, and the ethical and legal dilemmas linked to certain techniques.

\section{Acknowledgements}

This research was supported and funded by the Government of the Canary Islands and the European Social Fund.

\section{References}

Alawwad, Z., Alkowaileet, W., Alsubaiee, S., Alfaris, A., Alansari, M. M., \& Ragab, A. M. (2016). Analyzing Call Detail Records to Support Tourism Statistics in Saudi Arabia: An Exploratory Study. Paper presented at the 14th Global Forum on Tourism Statistics, 23-25 November 2016, Venice.

Baggio, R., \& Scaglione, M. (2018). Destination Attractions System and Strategic Visitor Flows. Paper presented at the International Conference on Web Engineering, June 2018, Cáceres.

Barton, T., \& Graf, M. (2018). Analysis of Travel Blogs Posted in New Zealand: Geographical Distribution, National Parks and Movie Locations. Journal of Advanced Management Science, 6(3), 139-142.

Boselie, P., Dietz, G., \& Boon, C. (2005). Commonalities and contradictions in HRM and performance research. Human Resource Management Journal, 15(3), 67-94.

Buhalis, D., \& Law, R. (2008). Progress in information technology and tourism management: 20 years on and 10 years after the Internet-The state of eTourism research. Tourism Management, 29(4), 609-623.

Dattilo, B., Radini, R., \& Sabato, M. (2016). How many SIM in your luggage? A strategy to make mobile phone data usable in tourism statistics. Paper presented at the 14th Global Forum on Tourism Statistics, 23-25 November 2016, Venice.

de Oliveira, R. A., \& Porto, R. M. A. B. (2016). Extração de dados do site Tripadvisor como suporte na elaboração de indicadores do turismo de Minas Gerais: Uma iniciativa em Big Data. Pesquisa Brasileira Em Ciência Da Informação e Biblioteconomia, 11(2), 26-37.

del Río-Rama, M. de la C., Maldonado-Erazo, C. P., \& Álvarez-García, J. (2018). State of the art of research in the sector of thermalism, thalassotherapy and spa: A bibliometric analysis. European Journal of Tourism Research, 19, 56-70.

Ding, Y., Chowdhury, G. G., \& Foo, S. (2001). Bibliometric cartography of information retrieval research by using co-word analysis. Information Processing $\mathcal{E}$ Management, 37(6), 817-842.

East, D., Osborne, P., Kemp, S., \& Woodfine, T. (2017). Combining GPS \& survey data improves understanding of visitor behaviour. Tourism Management, 61, 307-320.

Eccleston, R. E., Hardy, A. L., \& Hyslop, S. (2019). Unlocking the potential of tracking technology for cocreated tourism planning and development: Insights from the Tourism Tracer Tasmania project. Tourism Planning \& Development, 1-14.

European Union (200o). Charter of fundamental rights of the European Union., Official Journal of the European Communities. URL: http://www.europarl.europa.eu/charter/pdf/text_en.pdf

European Union (2007). Treaty of Lisbon. Official Journal of the European Union. URL: http://eurlex.europa.eu/legal-content/EN/TXT/?uri=celex\%3A12007L\%2FTXT

Eurostat. (2014). Feasibility Study on the use of Mobile Positioning Data for Tourism Statistics. Consolidated Report Eurostat Contract No 30501.2012. 001-2012.452, 31. 
Gallardo-Gallardo, E., Dries, N., \& González-Cruz, T. F. (2013). What is the meaning of 'talent' in the world of work? Human Resource Management Review, 23(4), 290-300.

Ginieis, M., Sánchez-Rebull, M.-V., \& Campa-Planas, F. (2012). The academic journal literature on air transport: Analysis using systematic literature review methodology. Journal of Air Transport Management, 19, 31-35.

Han, S., Ren, F., Wu, C., Chen, Y., Du, Q., \& Ye, X. (2018). Using the TensorFlow Deep Neural Network to Classify Mainland China Visitor Behaviours in Hong Kong from Check-in Data. ISPRS International Journal of Geo-Information, 7(4), 158.

Hardy, A., Aryal, J., \& Wells, M. (2019). Comparing techniques for tracking: The case of Tourism Tracer in Tasmania, Australia. E-Review of Tourism Research, 16(2/3), 84-94.

Hardy, A., Hyslop, S., Booth, K., Robards, B., Aryal, J., Gretzel, U., \& Eccleston, R. (2017). Tracking tourists' travel with smartphone-based GPS technology: A methodological discussion. Information Technology \& Tourism, 17(3), 255-274.

Huang, J., Li, Y., \& Li, H. (2014). Study on Factors to Adopt Mobile Payment for Tourism E-Business: Based on Valence Theory and Trust Transfer Theory. In Xiang, Z., \& Tussyadiah, I. (eds.) (2014) Information and Communication Technologies in Tourism 2014. Dublin: Springer.

Hyde, K. F., \& Lawson, R. (2003). The nature of independent travel. Journal of Travel Research, 42(1), 1323.

Ioannidis, J., Boyack, K. W., Small, H., Sorensen, A. A., \& Klavans, R. (2014). Bibliometrics: Is your most cited work your best? Nature News, 514(7524), 561.

Izquierdo Valverde, M., Prado Mascuñano, J., \& Velasco Gimeno, M. (2016). Same-day visitors crossing borders: A big data approach using traffic control cameras. Paper presented at the 14th Global Forum on Tourism Statistics, 23-25 November 2016, Venice.

Jiménez-Caballero, J. L., \& Polo Molina, S. (2017). A bibliometric analysis of the presence of finances in high-impact tourism journals. Current Issues in Tourism, 20(3), 225-232.

Kádár, B. (2014). Measuring tourist activities in cities using geotagged photography. Tourism Geographies, 16(1), 88-104.

Keul, A., \& Kühberger, A. (1997). Tracking the Salzburg tourist. Annals of Tourism Research, 24(4), 10081012.

Kiefer, P., Giannopoulos, I., Kremer, D., Schlieder, C., \& Raubal, M. (2014). Starting to get bored: An outdoor eye tracking study of tourists exploring a city panorama. Paper presented at the Proceedings of the Symposium on Eye Tracking Research and Applications, March 2014, New York.

Kirilenko, A. P., Stepchenkova, S. O., \& Hernandez, J. M. (2019). Comparative clustering of destination attractions for different origin markets with network and spatial analyses of online reviews. Tourism Management, 72, 400-410.

Konijn, E., Sluimer, N., \& Mitas, O. (2016). Click to share: Patterns in tourist photography and sharing. International Journal of Tourism Research, 18(6), 525-535.

Koo, T. T., Lau, P.-L., \& Dwyer, L. (2017). The Geographic Dispersal of Visitors: Insights from the Power law. Journal of Travel Research, 56(1), 108-121.

Krippendorff, K. (2004). Reliability in content analysis. Human Communication Research, 30(3), 411-433.

Lau, G., \& McKercher, B. (2006). Understanding tourist movement patterns in a destination: A GIS approach. Tourism and Hospitality Research, 7(1), 39-49.

Lau, P. L., Koo, T., \& Dwyer, L. (2017). Metrics to measure the geographic characteristics of tourism markets: An integrated approach based on Gini index decomposition. Tourism Management, 59, 171-181.

Leones, J., Colby, B., \& Crandall, K. (1998). Tracking expenditures of the elusive nature tourists of Southeastern Arizona. Journal of Travel Research, 36(3), 56-64. 
Leung, X. Y., Sun, J., \& Bai, B. (2017). Bibliometrics of social media research: A co-citation and co-word analysis. International Journal of Hospitality Management, 66, 35-45.

Liu, B., Huang, S. S., \& Fu, H. (2017). An application of network analysis on tourist attractions: The case of Xinjiang, China. Tourism Management, 58, 132-141.

Maldonado-Erazo, C. P., Durán-Sánchez, A., \& Álvarez-García, J. (2019). Mountain tourism research. A review. European Journal of Tourism Research, 22, 130-150.

McKercher, B., Hardy, A., \& Aryal, J. (2019). Using tracking technology to improve marketing: Insights from a historic town in Tasmania, Australia. Journal of Travel E Tourism Marketing, 36(7), 823834 .

McKercher, B., \& Lau, G. (2008). Movement patterns of tourists within a destination. Tourism Geographies, 10(3), 355-374.

McKercher, B., \& Zoltan, J. (2014). Tourist Flows and Spatial Behavior. The Wiley Blackwell Companion to Tourism, 33-44.

OECD (1980). Guidelines on the Protection of Privacy and Transborder Flows of Personal Data. OECD Guidelines. URL: http://www.oecd.org/sti/ieconomy/oecdguidelinesontheprotectionofprivacy andtransborderflowsofpersonaldata.htm

OECD (1998) Ministerial Declaration on the Protection of Privacy on Global Networks. OECD Guidelines. URL: http://www.oecd.org/internet/ieconomy/1840065.pdf

Padrón-Ávila, H., \& Hernández-Martín, R. (2019a). Preventing Overtourism by Identifying the Determinants of Tourists' Choice of Attractions. Sustainability, 11, 5177.

Padrón-Ávila, H., \& Hernández-Martín, R. (2019b). Why do tourists differ in their likelihood to visit attractions? The case of Lanzarote. International Journal of Tourism Research, 21(6), 790-80o.

Palmer, A. L., Sese, A., \& Montaño, J. J. (2005). Tourism and statistics: Bibliometric study 1998-2002. Annals of Tourism Research, 32(1), 167-178.

Raun, J., \& Ahas, R. (2016). Defining usual environment with mobile tracking data. Paper presented at the 14th Global Forum on Tourism Statistics, 23-25 November 2016, Venice.

Raun, J., Ahas, R., \& Tiru, M. (2016). Measuring tourism destinations using mobile tracking data. Tourism Management, 57, 202-212.

Renenger, A. (2001). Satellite tracking and the right to privacy. Hastings LJ, 53, 549.

Rudchenko, V., Martín, J.-C., \& Sánchez-Rebull, M.-V. (2017). Bibliometric analysis over research on “client satisfaction." Problems and Perspectives in Management, 15(1), 99-106.

Rudchenko, V., Martín, J.-C., \& Sánchez-Rebull, M.-V. (2018). Are there any differences in client satisfaction investigation within Scopus and Russian journal publications? Journal of Research on Trade, Management and Economic Development, 5(2), 55-76.

Sandbrook, C., \& Semple, S. (2006). The rules and the reality of mountain gorilla Gorilla beringei beringei tracking: How close do tourists get? Oryx, 40(4), 428-433.

Schreier, M. (2012). Qualitative content analysis in practice. Thousand Oaks: Sage Publications.

Seynaeve, G., \& Demunter, C. (2016). When mobile network operators and statistical offices meetIntegrating mobile positioning data into the production process of tourism statistics. Paper presented at the 14th Global Forum on Tourism Statistics, 23-25 November 2016, Venice.

Shoval, N., \& Ahas, R. (2016). The use of tracking technologies in tourism research: The first decade. Tourism Geographies, 18(5), 587-606.

Shoval, N., \& Isaacson, M. (2007). Tracking tourists in the digital age. Annals of Tourism Research, 34(1), 141-159.

Shoval, N., \& Isaacson, M. (2010). Tourist mobility and advanced tracking technologies. New York: Routledge.

Shoval, N., McKercher, B., Ng, E., \& Birenboim, A. (2011). Hotel location and tourist activity in cities. Annals of Tourism Research, 38(4), 1594-1612. 
Shoval, N., Schvimer, Y., \& Tamir, M. (2018). Real-time measurement of tourists' objective and subjective emotions in time and space. Journal of Travel Research, 57(1), 3-16.

Signorelli, S., Reis, F., \& Biffignandi, S. (2016). What attracts tourists while planning for a journey? An analysis of three cities through Wikipedia page views. Paper presented at the 14th Global Forum on Tourism Statistics, 23-25 November 2016, Venice.

Silva, F. P., Allbesmart, L., \& Rodrigues, J. (2016). Real-time tourists counting and tracking system for management of nature trails in Naturtejo Global Geopark (Portugal). Romanian Review Precision Mechanics Optics and Mechatronics, 10, 1-15.

Smallwood, C. B., Beckley, L. E., \& Moore, S. A. (2012). An analysis of visitor movement patterns using travel networks in a large marine park, north-western Australia. Tourism Management, 33(3), 517528.

Smith, D. R., \& Hazelton, M. (2008). Bibliometrics, citation indexing, and the journals of nursing. Nursing \& Health Sciences, 10(4), 260-265.

Thimm, T., \& Seepold, R. (2016). Past, present and future of tourist tracking. Journal of Tourism Futures, 2(1), 43-55.

Thornton, P., Williams, A., \& Shaw, G. (1997). Revisiting Time-Space Diaries: An Exploratory Case Study of Tourist Behaviour in Cornwall, England. Environment and Planning A, 29(10), 1847-1867.

United Nations. (1948). Universal Declaration of Human Rights. http://www.aprodeh.org.pe

United Nations (1990). Guidelines for the Regulation of Computerized Personal Data Files, United Nations General Assembly, 45. URL: http://www.un.org/es/comun/docs/?symbol=\%2oA/ RES/45/95\&Lang=S

Visser, G. (2014). Gay and Lesbian Tourism Practices. The Wiley Blackwell Companion to Tourism, 435444 .

Waitt, G., \& Markwell, K. (2006). Gay tourism: Culture and context. Psychology Press.

Wang, X., Li, X. R., Zhen, F., \& Zhang, J. (2016). How smart is your tourist attraction: Measuring tourist preferences of smart tourism attractions via a FCEM-AHP and IPA approach. Tourism Management, 54, 309-320.

Yun, H. J., Kang, D. J., \& Lee, M. J. (2018). Spatiotemporal distribution of urban walking tourists by season using GPS-based smartphone application. Asia Pacific Journal of Tourism Research, 23(11), 1047-1061.

Zoltan, J., \& Masiero, L. (2012). The relation between push motivation and activity consumption at the destination within the framework of a destination card. Journal of Destination Marketing $\mathcal{E}$ Management, 1(1), 84-93.

Zoltan, J., \& McKercher, B. (2015). Analysing intra-destination movements and activity participation of tourists through destination card consumption. Tourism Geographies, 17(1), 19-35.

Received: $16 / 10 / 2019$

Accepted: 02/01/2020

Coordinating editor: Stanislav Ivanov 